\title{
IMPLEMENTASI PENDIDIKAN KARAKTER DISIPLIN DENGAN MEMBERI IDENTITY CARD DI KELOMPOK A
}

\begin{tabular}{|c|c|}
\hline \multicolumn{2}{|c|}{ 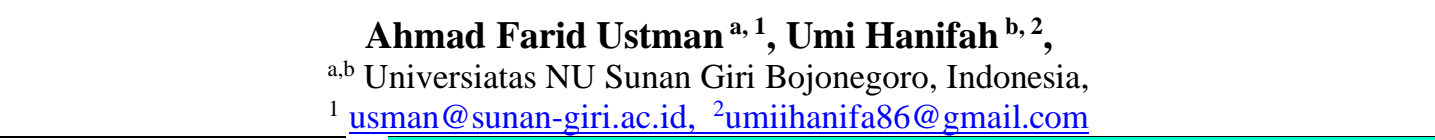 } \\
\hline Informasi artikel & ABSTRAK \\
\hline $\begin{array}{l}\text { Received : } \\
\text { September 9, } 2021 . \\
\text { Revised : } \\
\text { September 13, } 2021 . \\
\text { Publish : } \\
\text { September 23, } 2021 . \\
\text { Kata kunci: } \\
\text { Pendidikan karakter; } \\
\text { Disiplin; } \\
\text { Identity card; }\end{array}$ & $\begin{array}{l}\text { Penelitian ini bertujuan untuk mengetahui Pembelajaran Pendidikan } \\
\text { Karakter Disiplin. Penelitian ini merupakan penelitian deskriptif } \\
\text { kualitatif. Bertempat di RA Islamiyah Bulaklo. Data dikumpulkan } \\
\text { dengan observasi, wawancara, dan dokumentasi. Data yang telah } \\
\text { terkumpulkan diperiksa keabsahannya dengan triangulasi sumber } \\
\text { dan triangulasi teknik. Dianalisis dengan teknik analisis interaktif } \\
\text { yaitu pengumpulan data, reduksi data, penyajian data, dan verifikasi } \\
\text { atau kesimpulan. Informan penelitian yaitu ketua yayasan, kepala } \\
\text { sekolah, guru,dan wali murid. Hasil penelitian menunjukkan bahwa } \\
\text { pemberian Id Card, peserta didik dapat berbaris dengan rapi, } \\
\text { meletakkan sepatu dan tas ditempatnya sesuai urutan di Identity card } \\
\text { yang menjadikan peserta didik lebih disiplin dan sabar menunggu } \\
\text { giliran. Dari penelitian ini dapat di tarik kesimpulan bahwa dalam } \\
\text { Implementasi pendidikan karakter anak usia dini (4-5 tahun) di RA } \\
\text { Islamiyah Bulaklo dalam menerapkan pendidikan karakter } \\
\text { menggunakan kegiatan pembiasaan mulai anak masuk gerbang } \\
\text { sampai pulang sekolah. Untuk kegiatan pembiasaan seperti berbaris, } \\
\text { berdoa, hafalan asmaul husna, cuci tangan, dan lainnya itu dengan } \\
\text { memberikan pengertian kepada anak-anak selalu bersabar menunggu } \\
\text { giliran sesuai nomer di Identity Card. }\end{array}$ \\
\hline & ABSTRACT \\
\hline $\begin{array}{l}\text { Keywords: } \\
\text { Character education; } \\
\text { Discipline; } \\
\text { Identity card. }\end{array}$ & $\begin{array}{l}\text { This study aims to determine the Discipline Character Education } \\
\text { Learning. This research is a qualitative descriptive study. Located at RA } \\
\text { Islamiyah Bulaklo. Data were collected by observation, interviews, and } \\
\text { documentation. The data that has been collected is checked for validity } \\
\text { by source triangulation and technical triangulation. Analyzed with } \\
\text { interactive analysis techniques, namely data collection, data reduction, } \\
\text { data presentation, and verification or conclusions. Research informants } \\
\text { are the head of the foundation, principal, teachers, and guardians of } \\
\text { students. The results showed that by giving Id Cards, students could line } \\
\text { up neatly, put shoes and bags in their place according to the order on the } \\
\text { Identity card which made students more disciplined and patiently waiting } \\
\text { for their turn. From this study, it can be concluded that in the } \\
\text { implementation of character education for early childhood (4-5 years) at } \\
\text { RA Islamiyah Bulaklo in implementing character education using } \\
\text { habituation activities starting from the child entering the gate until going } \\
\text { home from school. For habituation activities such as marching, praying, } \\
\text { memorizing Asmaul Husna, washing hands, and so on, by giving } \\
\text { understanding to children, always be patient waiting for their turn } \\
\text { according to the number on the Identity Card. }\end{array}$ \\
\hline
\end{tabular}

This work is licensed under a Creative Commons Attribution-ShareAlike 4.0 International License. Allows readers to read, download, copy, distribute, print, search, or link to the full texts of its articles and allow readers to use them for any other lawful purpose. 


\section{PENDAHULUAN}

Dalam Undang-Undang Sistem Pendidikan Nasional (SISDIKNAS) Nomor 20 Tahun 2003 Pasal 3 menyebutkan bahwa: Pendidikan bertujuan mengembangkan kemampuan dan membentuk watak serta peradaban yang bermartabat dalam rangka mencerdaskan kehidupan bangsa, bertujuan untuk berkembangnya potensi peserta didik agar menjadi manusia yang beriman dan bertakwa kepada Tuhan Yang Maha Esa,berakhlak muliasehat, berilmu, cakap, kreatif, mandiri, dan menjadi warga negara yang demokratis serta bertanggung jawab.

Menurut (Munawik Shaleh, 2012) membangun karakter bersifat memperbaiki, membina, mendirikan, mengadakan sesuatu. Sedangkan "Karakter" adalah tabiat, watak, sifat-sifat kejiwaan, akhlak atau budi pekerti yang membedakan seseorang dari yang lain. Dalam konteks disini adalah suatu proses atau usaha yang dilakukan untuk membina, memperbaiki dan atau membentuk tabiat, watak, sifat kejiwaan, akhlak mulia, insan manusia sehingga menunjukan perangai dan tingkah laku yang baik berlandaskan nilai-nilai Pancasila. Membangun karakter anak usia dini tidak hanya disekolah, Orang Tua juga harus terlibat dalam membentuk dan menanamkan karakter yang baik pada anak. Sebagaimana Firman Allah SWT:

"Hai anakku, dirikanlah shalat dan suruhlah (manusia) mengerjakan yang baik dan cegahlah (mereka) dari perbuatan yang mungkar dan bersabarlah terhadap apa yang menimpa kamu. Sesungguhnya yang demikian itu Termasuk hal-hal yang diwajibkan (oleh Allah). dan janganlah kamu memalingkan mukamu dari manusia (karena sombong) dan janganlah kamu berjalan di muka bumi dengan angkuh. Sesungguhnya Allah tidak menyukai orang-orang yang sombong lagi membanggakan diri”.'(QS. Luqman:17-18)

artinya ayat ini menjelaskan kita sebagai manusia dari yang kecil hingga dewasa harus lah berakhlak yang baik. Karena Karakter atau watak merupakan komponen yang sangat penting agar manusia dapat mencapai tujuan hidupnya dengan baik dan selamat. Karakter memegang peran yang sangat utama dalam menentukan sikap dan perilaku. 
Menurut (Yuliani, 2012) Pada usia 0 sampai 6 tahun merupakan usia yang sangat menentukan dalam pembentukan karakter dan kepribadian seorang anak. Usia itu sebagai usia penting bagi pengembangan intelegensi permanen dirinya, mereka juga mampu menyerap infomasi yang sangat tinggi. Anak belajar dengan cara mengamati, meniru dan bereksperimen, jika anak dibiasakan untuk disiplin dan sabar baik. dirumah maupun disekolah dengan cara yang paling mudah dimengerti anak, sedikit demi sedikit anak pasti akan terbiasa untuk bersikap disiplin dan bersabar walaupun tidak didampingi oleh guru mereka.

Menurut (Lickona, 2016) Pendidikan karakter mencakup tiga unsur pokok, yaitu pengetahuan moral/kebaikan, perasaan moral/mecintai kebaikan dan tindakan mora/melakukan kebaikan. Tujuan pendidikan karakter yaitu memahami dan menghayati nilai-nilai karakter yang ada, kemudian dari nilai-nilai karakter yang sudah dipahami dan dihayati tersebut dijadikan sebagai pedoman setiap melakukan perbuatan agar menjadi kebiasaan.

Disiplin merupakan salah satu nilai karakter yang sangat penting untuk ditanamkan pada anak. Kedisiplinan pada anak usia dini tidak muncul secara tibatiba, tetapi dimulai melalui rutinitas yang dilakukan secara konsisten setiap hari. Terkait nilai pendidikan karakter yang perlu ditanamkan pada anak usia dini, salah satunya adalah disiplin terutama disiplin dalam bersabar dalam menunggu giliran sebab disiplin membentuk kebiasaan atau perilaku. Tujuan disiplin pada anak adalah untuk mengarahkan anak agar mereka belajar mengenai hal-hal baik yang merupakan persiapan bagi masa dewasa, saat mereka sangat bergantung kepada disiplin diri. Kapan dan bagaimana cara menerapkan disiplin sangat bervariasi, bergantung pada tahap perkembangan dan temperamen masing-masing anak.

Jadi pola penerapan disiplin merupakan suatu gambaran yang menjelaskan tentang bagaimana cara atau proses seseorang dalam membentuk karakter terutama karakter kedisiplinan, dengan terbentunya karakter kedisiplinan pada jiwa seseorang maka seseorang tersebut akan mempunyai kepribadian yang baik seperti, bersikap jujur dalam segala hal dan menaati peraturan-peraturan yang ada. Penerapan disiplin juga menerapkan tentang hidup yang teratur, tidak amburadul dalam kehidupan yang terpola secara rapi. 
Antri atau sabar menunggu giliran adalah kegiatan di tempat-tempat tertentu dimana sekumpulan orang harus mematuhi urutan mendapat giliran untuk memperoleh kesempatan atau barang tertentu. Sebagai suatu sikap mental antri memang terkait erat kepada disiplin diri pribadi, dan disiplin masyarakat dimana individu berada. Aktivitas antri atau sabar menunggu giliran bukan merupakan hal yang baru, antri atau sabar menunggu giliran timbul disebabkan oleh kebutuhan akan layanan melebihi kemampuan (kapasitas) pelayanan dan fasilitas layanan, sehingga pengguna fasilitas yang tiba tidak bisa segera mendapat layanan disebabkan kesibukan layanan. Antri atau sabar menunggu giliran merupakan perilaku sosial sekumpulan orang yang memiliki minat dan kebutuhan yang sama dan sama-sama ingin dan berkepentingan untuk memenuhinya, akan tetapi karena adanya tuntutan waktu dan keterbatasan sumber daya memaksa setiap orang mengikuti aturan pelayanan secara bergiliran.

Terkait kedisiplinan menurut Kemendiknas (2012:20) menyebutkan bahwa indikator disiplin pada anak usia 4-5 tahun, yaitu: (1) selalu datang tepat waktu, (2) dapat memperkirakan waktu yang diperlukan untuk menyelesaikan sesuatu, (3) menggunakan benda sesuai dengan fungsinya, (4) mengambil dan mengembalikan benda pada tempatnya, (5) berusaha mentaati aturan yang telah disepakati, (6) sabar menunggu giliran, (7) menyadari akibat bila tidak disiplin. Pada usia anak-anak perilaku disiplin sangat sulit dilakukan karena biasanya anak itu susah diatur. Misalkan pada waktu baris anak- anak sulit sekali dikondisikan untuk berbaris dengan rapi, belum lagi ketika anak-anak masuk kelas, mereka akan berlarian untuk sampai dikelas. Ketika melepas sepatu dan tas anak-anak biasanya meletakkan sepatu dan tas seenaknya. Pada waktu duduk anak-anak akan berebut tempat disamping bu guru. Setiap pembagian buku anak-anak berebut ingin mendapatkan buku secepatnya. Pada waktu cuci tangan biasanya anak akan saling dorong mendorong.

\section{METODE}

Pendekatan yang digunakan dalam penelitian skripsi ini adalah pendekatan kualitatif, dimana penelitian ini mempunyai ciri khas terletak pada tujuannya, yakni mendeskripsikan tentang segala sesuatu yang berkaitan dengan keseluruhan 
kegiatan pada proses pembelajaran yang berkaitan dengan keseluruhan kegiatan pada proses pembelajaran untuk mencapai tujuan yang diinginkan. Lokasi penelitian terletak di RA Islamiyah yang terletak di Rt 07 Rw. 02 Desa Bulaklo Kecamatan Balen Kabupaten Bojonegoro. Ternik pengumpulan data dilakukan melalui observasi, wawancara dan dokumentasi. Uji keabsahan data menggunakan tehnik pengumpulan data (trianggulasi). Tehnik trianggulasi adalah tehnik pemeriksaan keabsahan data yang memanfaatkan sesuatu yang lain

\section{PEMBAHASAN}

Identity card adalah kartu identitas atau kartu pengenal. Identity Card disini adalah sebuah kalung yang yang berisi angka sesuai jumlah peserta didik. Identity Card ini akan diberikan kepada peserta didik menurut urutan kedatangan. Angka yang ada di kalung Identity Card akan digunakan sebagai urutan dalam meletakkan sepatu, menaruh tas di rak, duduk dibangku, berbaris, cuci tangan dan urutan pulang sekolah. Identity Card anak-anak bisa terbiasa disiplin dalam menunggu giliran serta dapat melatih agar anak-anak lebih bersabar dalam menunggu giliran dan tidak berebut untuk melakukan kegiatan pembelajaran disekolah. Karena anak yang mendapat Identity Card nomer urut satu maka ai akan mendapat kesempatan untuk melakukan kegiatan pembelajaran yang pertama.

Pendidikan karakter adalah pendidikan yang diusahakan dan direncanakan oleh pendidik dalam menanamkan nilai-nilai karakter kepada diri peserta didik agar dapat berperilaku positif dalam menjalin hubungan dengan Tuhan, dirinya sendiri, orang lain, dan makhluk ciptaan Tuhan, berpikir religious, kreatif, nasionalis, dan produktif.

"Ibu Lilik mahfudhoh, S.Pd.I mengemukakan bahwa implementasi pendidikan karakter di RA Islamiyah Bulaklo dilakukan melalui kegiatan pembiasaan yang dilakukan mulai penyambutan peserta didik sampai peserta didik pulang sekolah. Kegiatan pembiasaan di RA Islamiyah Bulaklo direncanakan dan dilaksanakan setiap harisesuai dalam RPPH. Untuk jenis kegiatannya yaitu menyambut peserta didik dengan berjabat tangan dan mengucapkan salam serta mengambil kalung nomer (idendity card) sesuai urutan kedatanganya dan meletakakan sepatu sesuai nomer di idendity card kemudian meletakkan tas di loker sesuai nomer di idendity card. Setelah itu berbaris sesuai dengan nomer di idendity card, berikrar, berdo'a sebelum kegiatan pembelajaran, asmaul husna bersama, bernyanyi bersama dan melakukan permainan pagi. Ketika anak-anak 
melakukan permainan pagi juga sesuai dengan nomor di idendity card. kemudian anak-anak itu masuk kelas dan duduk di bangku sesuai dengan nomor di idendity card. Ketika melakukan cuci tangan sebelum dan sesudah makan sebagi pembiasaan hidup sehat anak anak-anak itu mengantri sesuai dengan nomor di idendity card. Ketika pulang sekolah anak-anak dipanggil sesuai dengan nomor di idendity card. Ini dilakukan untuk melatih anak-anak supaya disiplin dan bisa bersabar dalam menunggu giliran"

Implementasi pendidikan karakter RA Islamiyah Bulaklo dilakukan dengan membuat Standar Operasional Prosedur (SOP), Berikut penuturan Ibu ninik Rohmawati, S.Pd :

a. Penyambutan

"Setiap pagi guru-guru disini selalu menyambut anak-anak di depan gerbang dengan berjabat tangan agar tidak ada jarak antara murid dengan guru. Prosesnya yaitu menyambut kehadiran anak selama 15 menit sebelum jam masuk, salaman dengan senyum dan menanyakan kabar hari ini serta memberi Identity Card sesuai urutan kedatangan.

b. Meletakkan tas dan sepatu

" setiap peserta didik menaruh sepatu dan tas sesuai nomer di Identity Card. Prosesnya Guru memberi angka di tempat meletakkan sepatu dan loker tas, anak-anak akan meletakkan sepatu dan tas sesuai dengan kalung Identity card. Tujuannya agar anak-anak dapat meletakkan barang di tempatnya sesuai nomer di Identity Card".

c. Berbaris

" peserta didik berbaris sesuai nomer di Identity Card. Tujuannya agar anak-anak dapat berbaris dengan disiplin dan rapi”. Karena bugu sudah mempersiapkan tempat berbaris yang lantainya sudah diberi angka, anak-anak dengan otomatis berdiri diatas angka tersebut sesuai dengan kalung Identity card".

d. Masuk kelas

" peserta didik masuk kelas sesuai nomer di Identity Card. Tujuannya supaya anak masuk kelas dan duduk dengan rapi sesuai nomer di Identity Card". Prosesnya Setiap bangku sudah di beri angka terlebih dahulu supaya anak-anak duduk sesuai dengan kalung Identity card. Jadi anak-anak tidak ada yang berebut tempat duduk.

e. Cuci tangan

"Cuci tangan mengajarkan kepada anak-anak untuk selalu hidup sehat. Prosesnya dengan menyiapkan peralatan cuci tangan seperti sabun dan serbet, anak-anak antri menunggu giliran sambil berbaris sesuai nomer di Identity Card, mencuci tangan dengan aturan yang benar sesuai standar cuci tangan”. Satu persatu anak cuci tangan sesuai dengan kalung Identity card.

f. Pulang sekolah 
"Ketika pulang ini kita mengajarkan kepada anak-anak untuk sabar menunggu giliran sesuai nomer di Identity Card tidak boleh menangis. Prosesnya yaitu setelah selesai berdo"a anak-anak mengucapkan salam dan dan Tanya jawab dengan ibu guru sesuai nomer di Identity Card, anak-anak dipersilahkan pulang jika sudah bisa menjawab tpertanyaan bu guru, anak-anak dilatih pulang membawa tas sendiri"

\section{Tujuan Pendidikan Karakter}

Menurut Ibu Lilik Mahfudhoh, S.Pd.I selaku Kepala RA Islamiyah Bulaklo "pendidikan karakter disiplin diterapkan kepada peserta didik bertujuan supaya berperilaku baik dan sabar menunggu giliran, seperti meletakkan sepatu dan tas di tempat yg sudah disediakan akan mengajarkan anak menaruh barang di tempatnya dan sesuai nomer di Identity Card, melakukan baris setiap hari sesuai dengan nomer urutan di Identity Card dengan tujuan menerapkan pendidikan karakter disiplin, mencuci tangan sebelum dan sesudah makan dengan tujuan agar peserta didik dapat menjaga kesehatan dan kebersihan, pendidik selalu menyambut peserta didik dengan tujuan agardapat mengucap salam dan menghargai orang lain, membereskan alat permainan setelah selesai bermain dengan tujuan agar peserta didik dapat bertanggungjawab. Dengan cara-cara tersebut sebagi pendidik dapat mengajarkan pendidikan karakter agar kelak menjadi penerus bangsa yang baik"

Selain tujuan yang dikemukakan Ibu Lilik Mahfudhoh, Ibu Siti Nur Faizah, S.Pd juga menambahkan bahwa :

"tujuan pendidikan karakter yaitu supaya anak memiliki kebiasaan baik yang melekat pada diri peserta didik.

Hal ini sesuai dengan dokumen Kurikulum RA Islamiyah Bulaklo.

\section{Kegiatan Pembiasaan di RA Islamiyah}

\section{Bulaklo}

\begin{tabular}{|c|c|}
\hline No & Bentuk bentuk pelaksanaan kegiatan \\
\hline 1 & $\begin{array}{l}\text { a. Bersalaman sambil mengucap salam dengan pendidik } \\
\text { b. Meletakkan sepatu sesuai nomer urutan kedatangan } \\
\text { c. Mengambil nomer Identity Card dan dipakai di leher } \\
\text { d. Meletakkan tas di loker sesuai nomer di Identity Card } \\
\text { e. Peserta didik dibiasakan mengucap terimakasih, } \\
\text { permisi tolong, maaf }\end{array}$ \\
\hline
\end{tabular}

2 a. Berbaris sesuai nomer di Identity Card

b. Berdoa sebelum kegiatan pembelajaran

c. Menghafalkan asmaul husna

d. Menghafalkan hadits-hadits 


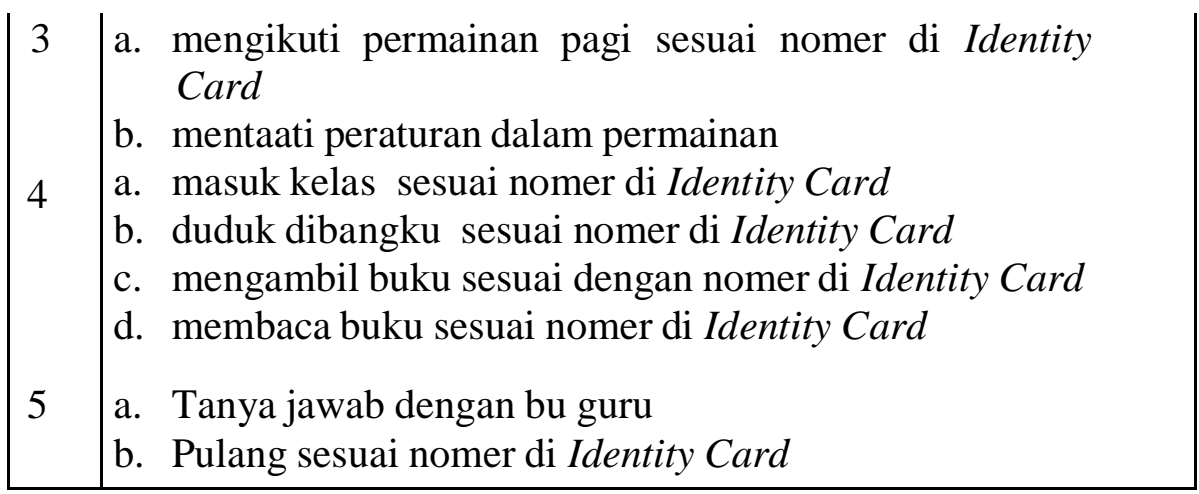

Bentuk-bentuk kegiatan pembiasaan dilakukan mulai dari anak masuk gerbang sampai penjemputan. penuturan Ibu Lilik Mahfudhoh, S.Pd.I

"Kegiatan pembiasaan yang diterapkan disini itu diawali mulai dari anak masuk gerbang sampai pulang sekolah. Jadi ini bisa dikatakan sebagai proses awal penerapan pendidikan karakter disiplin kepada anak-anak. Kalau proses pembiasaan di dalam kelas sebelum melakukan kegiatan pembelajaran ya dengan memberikan pengertian kepada anak-anak untuk duduk yang rapi sesuai nomer di Identity Card dan tidak gaduh ketika berada di dalam kelas. Untuk kegiatan pembiasaan seperti berbaris, berdoa, hafalan asmaul husna, cuci tangan, dan lainnya itu dengan memberikan pengertian kepada anak-anak selalu bersabar menunggu giliran sesuai nomer di Identity Card. Jadi semua kegiatan pembiasaan tersebut mengajarkan kepada anak-anak penerapan pendidikan karakter disiplin, sabar menunggu giliran, tanggung jawab, toleran, dan nilai-nilai karakter lainnya"

\section{Kegiatan Keteladanan}

Keteladanan adalah kegiatan yang dapat ditiru dan dijadikan

panutan.Seorang pendidik harus menunjukkan perilaku konsisten dalam mewujudkan nilai-nilai karakter yang dapat diamati oleh peserta didik sehari-hari baik di dalam maupun di luar lembaga. Berdasarkan hasil observasi selama di RA Islamiyah Bulaklo, bentuk-bentuk keteladanan yang diterapkan kepada peserta didik adalah sebagai berikut:

\section{Tabel Kegiatan Keteladanan di RA Islamiyah Bulaklo}

\begin{tabular}{|l|l|}
\hline No & Bentuk-bentuk pelaksanaan kegiatan keteladanan \\
\hline 1 & $\begin{array}{l}\text { a. Pendidik berdoa bersama dengan peserta didik } \\
\text { b. Pendidik mengajarkan sikap doa yang baik } \\
\text { c. Pendidik mengatakan maaf, terimakasih, permisi, } \\
\text { minta tolong }\end{array}$ \\
\hline 2 & $\begin{array}{l}\text { a. Pendidik menyampaikan sesuatu dengan sopan dan } \\
\text { tidak teriak }\end{array}$ \\
\hline
\end{tabular}




\begin{tabular}{|c|c|}
\hline & $\begin{array}{l}\text { b. Pendidik menggunakan bahasa Indonesia dengan ba } \\
\text { dan benar }\end{array}$ \\
\hline 3 & $\begin{array}{l}\text { a. Pendidik memberikan perhatian yang sama kepada } \\
\text { peserta didik } \\
\text { b. Pendidik menepati janji }\end{array}$ \\
\hline 4 & $\begin{array}{l}\text { a. Pendidik melakukan senam bersama peserta didik Pendidik } \\
\text { b. mendampingi peserta didik yang lomba Pendidik } \\
\text { c. mengantar dan mengajarkan cara bercuci tangan yang } \\
\text { benar kepada peserta didik }\end{array}$ \\
\hline
\end{tabular}

Bentuk-bentuk kegiatan keteladanan dilakukan dengan harapan peserta didik dapat menirukan apa yang dicontohkan pendidik. Berikut penuturan Ibu Ninik Rohmawati.

"Disini kita sebagai pendidik bukan hanya memberikan pembiasaan kepada anak-anak tanpa memberikan contoh, jadi selama ini kita juga memberikan keteladanan supaya anak-anak dapat mencotoh apa yang sudah dilakukan oleh ibu gurunya. Karena dengan contoh anak-anak akan lebih paham menjalankan pembiasaan-pembiasaan yang diterapkan".

Hal ini sesuai dengan dokumen RPPH dan SOPRA Islamiyah Bulaklo.

\section{Identity Card dalam Pendidikan Karater disiplin di RA}

Identity card adalah kartu identitas atau kartu pengenal. Identity card di RA Islamiyah ini berupa kalung yang telah diberi angka sesuai jumlah kelompok. Untuk kelompok A yang berjumlah 17 anak maka kalung Identity card ini berjumlah 17 buah yang telah di beri angka 1-17. Setiap anak akan mendapat satu kalung Identity card sesuai urutan kedatangan.

Manfaat yang diperoleh dari pemberian kalung Identity card adalah sebagai berikut:

1. Terbiasa disiplin

2. Memahami hak orang lain

3. Sabar menunggu giliran

4. Terbiasa antri

5. Terbiasa meletakkan sepatu dengan rapi

6. Terbiasa meletakkan tas dengan rapi

7. Terbiasa baris dengan tertib dan rapi

8. Masuk kelas dengan tertib dan rapi

9. Duduk sesuai urutan dengan rapi 


\section{Cuci tangan dengan berbaris rapi}

\section{Pulang sekolah satu persatu dengan tertib}

Sabar menunggu giliran adalah suatu perwujudan dari sikap kedisiplinan sosial untuk mencapai pelaksanaan suatu kegiatan secara tertib dan lancar. Untuk itu diperlukan aturan agar tertib dan lancar. Unsur yang paling terpenting adalah sistem bergilir menurut urutan kedatangan, dimana orang yang lebih dulu datang dan lebih siap akan memperoleh kesempatan lebih dahulu. Pada anak usia dini. kedisiplinan dalam menunggu giliran harus dibiasakan terus menerus agar anak dapat bersabar dalam menunggu giliran.

\section{KESIMPULAN}

Implementasi pendidikan karakter anak usia dini (4-5 tahun) di RA Islamiyah Bulaklo dalam menerapkan pendidikan karakter menggunakan kegiatan pembiasaan mulai anak masuk gerbang sampai pulang sekolah. Adapun jenis kegiatannya antara lain : Kegiatan pembiasaan yang diterapkan diawali mulai dari anak masuk gerbang sampai pulang sekolah . Jadi ini bisa dikatakan sebagai proses awal penerapan pendidikan karakter disiplin kepada anak-anak. Kalau proses pembiasaan di dalam kelas sebelum melakukan kegiatan pembelajaran ya dengan memberikan pengertian kepada anak-anak untuk duduk yang rapi sesuai nomer di Identity Card dan tidak gaduh ketika berada di dalam kelas. Untuk kegiatan pembiasaan seperti berbaris, berdoa, hafalan asmaul husna, cuci tangan, dan lainnya itu dengan memberikan pengertian kepada anak-anak selalu bersabar menunggu giliran sesuai nomer di Identity Card. Jadi semua kegiatan pembiasaan tersebut mengajarkan kepada anak-anak penerapan pendidikan karakter disiplin, sabar menunggu giliran, tanggungjawab, toleran, dan nilai-nilai karakter lainnya". Kegiatan-kegiatan pembiasaan dilakukan dengan tujuan untuk membentuk karakter disiplin peserta didik, supaya disiplin, sabar menunggu giliran, dan meletakkan barang sesuai tempatnya. Pada dasarnya implementasi pendidikan karakter disiplin sangat berperan penting bagi anak usia dini. Karena dengan mengimplementasikan pendidikan karakter disiplin sejak dini memberikan pengaruh besar bagi karakter generasi muda kedepan untuk menjadi lebih baik. 
Faktor Pendukung Pembelajaran Pendidikan Karakter Disiplin Dengan Memberi Identity Card di Kelompok A RA Islamiyah Bulaklo antara lain: 1) Kesadaran anak dalam melaksanakan kegiatan pembelajaran sesuai dg nomer urutan. 2) Antusias anak ketika mengikuti proses pemberian Identity Card. 3) Keteladanan dari pendidik. 4) Motivasi pendidik kepada peserta didik. 5) Sarana dan Prasarana yang Memadai.

\section{REFERENSI}

Abdul Majid, 2011, Pendidikan Karakter Perspektif Islam, PT Remaja Rosdakarya , Bandung

Abdullah, Ridwan Sani dan Muhammad Kadri, 2016, Pendidikan Karakter: Membangun Karakter Anak Yang Islami, PT Bumi Aksara, Jakarta

Ali Nugraha dan Yeni Rahmawati, 2012, Metode Pengembangan Sosial Emosional, Universitas terbuka, Tanggerang Selatan

Arifin, Zainal. 2010.Metodologi Penelitian Pendidikan, Lentera Cendikia Surabaya Asmani, Jamal Ma'mur. 2012. Buku Panduan Internalisasi Pendidikan Karakter di Sekolah. Diva Press Jogjakarta

Aulia,Choirun Nisak, 2013, Penanaman disiplin pada anak usia dini. Pedagogia, Bandung

Dahlan, Zaini. Qur'an Karim dan termahan artinya. UII Press Yogyakarta

Departemen Pendidikan Nasional. kamus Besar Bahasa Indonesia. PT Gramedia Pustaka Utama Jakarta

Departemen Pendidikan Nasional, 2006 Undang-Undang RI No. 20 Tahun 2003 Tentang system Pendidikan Nasional,: Biro Hukum dan Organisasi Sekretariat Jendral Departemen Pendidikan Nasional, Jakarta

Departemen Pendidikan Nasional, 2014, Peraturan Menteri pendidikan Nasional no 137 Tahun 2014 tentang Sistem Pendidikan Nasional Biro Hukum dan Organisasi

Sekretariat Jendral Departemen Pendidikan Nasional, Jakarta

Fatmawati,Wiwik. 2014. "Peran guru dalam penanaman akhlakul karimah pada anak usia dini", (skripsi fakultas tarbiyah, Institut agama Islam sunan giri bojonegoro).

Hamid,Hamdani MA dan Drs. Beni Ahmad Saebani, 2013. M.Si, Pendidikan Karakter perspektif islam, CV Pustaka Setia Bandung

Kesuma, Dharma. 2012, Pendidikan Karakter: kajian teori dan praktis di sekolah. PT Remaja Rosdakarya. Bandung

Koesuma, Doni. 2010. Pendidikan Karakter: Strategi Mendidik Anak di Zaman Global. Grasindo. Jakarta

Lestiono, Riski. 2018 Pembelajaran Interkultural berbasis pendidikan karakter. Universitas Muhammadiyah Malang

Mahbubi, M.2012. Pendidikan Karakter: Implmentasi Aswaja sebagai Nilai Pendidikan Karakter. Pustaka Ilmu Yogyakarta

Mansur, 2011, Pendidikan Anak Usia Dini Dalam Islam, Pustaka Belajar

Marzuki. 2015. Pendidikan Karakter Islam. Amzah. Jakarta 
Moleong,Lexy J. 2012. Metodologi Penelitian Pendidikan, PT Rineka Cipta. Jakarta Permendikbud Nomor 137 Tahun 2014 tentang Standar Nasional Pendidikan Anak Usia Dini

Prastowo, dkk. 2014. pedoman penulisan skripsi, UIN Sunan Kalijaga. Yogyakarta Remaja Rosdakarya. Bandung

Rimm, Sylvia. 2003. Mendidik dan menerapan disiplin pada anak prasekolah: pola asuhan masa kini. Gramedia Pustaka Utama. Jakarta

Saleh, Muwafik. 2012. Membangun Karakter Dengan Hati Nurani. Erlangga Jakarta

Sugiyono, 2007. Metode Penelitian Administrasi, Alfabeta , Bandung

Sujiono, Yuliani Nurani. 2012. Konsep Dasar Pendidikan Anak Usia Dini. indeks Jakarta.

Wibowo, Agus. 2012. Pendidikan karakter usia dini: strategi membangun karakter di usia emas. Pustaka Pelajar. Yogyakarta

Hasil wawancara dengan Bapak Drs. Moh. Khozin, ketua yayassan Al- Ma'ruf, 20 Juni 2019.

Hasil wawancara dengan Ibu Lilik Mahfudhoh, S.Pd.I, Kepala Sekolah RA Islamiyah Bulaklo, 21 Juni 2019

Hasil wawancara dengan Ibu Ninik Rohmawati, S.Pd, Dewan Guru RA Islamiyah Bulaklo,, 22 Juni 2019.

Hasil wawancara dengan Ibu Siti Nur Faizah, S. Pd. Dewan Guru RA Islamiyah Bulaklo, 22 Juni 2019

Wiyani, Novan Ardy. 2016. Konsep Dasar PAUD. Gava Media. Yogyakarta

Yaumi, Muhammad . 2014.Pendidikan Karakter : Landasan, Pilar dan Implementasi, Prenadamedia Group Jakarta. 